Titulo do Trabalho

\title{
ANÁLISE DO TEOR DE GLICEROL NO PROCESSO DE PRODUÇÃO DE BIODIESEL ETÍLICO DE ÓLEO DE SOJA POR ULTRAFILTRAÇÃO COM MEMBRANAS CERÂMICAS.
}

\author{
Nome do Autor (a) Principal \\ Janaina dos Santos de Miranda.
}

Nome (s) do Coautor (a) (s)

Gabriela Lela da Igreja; Gredson Keiff Souza.

Nome (s) do Orientador (a) (s)

Nehemias Curvelo Pereira; Maria Carolina Sérgi Gomes.

Instituição ou Empresa

\section{Universidade Estadual de Maringá.}

Instituição (s) de Fomento

\section{Universidade Estadual de Maringá.}

E-mail de contato

janamiranda.eq@gmail.com

Palavras-chave

Biodiesel. Membranas cerâmicas. Ultrafiltração.

\section{INTRODUÇÃO}

A preocupação constante com os impactos ambientais causados pela emissão de gases poluentes e a tendência de escassez de petróleo impulsionaram a discussão sobre o uso do biodiesel, que é combustível biodegradável, não tóxico, essencialmente livre de compostos sulfurados e aromáticos, e produz queima mais limpa. (Biodiesel B20, 2013). O método mais comum para produção de biodiesel é a transesterificação, em que triacilgliceróis presentes nos óleos e gorduras reagem com álcool na presença de catalisador originando uma mistura final composta por ésteres alquílicos de ácidos graxos, 
álcool residual, glicerol, catalisador e glicerídeos. Estes e outros contaminantes presentes no biodiesel podem causar problemas operacionais e ambientais e devem ser separados para que os ésteres possam ser utilizados como combustível (VAN GERPEN et al., 2004).

Os métodos convencionais de separação do glicerol são a decantação e a centrifugação. Ambos apresentam desvantagens como o longo tempo requerido na decantação e o custo elevado das centrífugas (VAN GERPEN et al., 2004). Sendo assim, um processo alternativo de separação, utilizando membranas, apresenta muitas vantagens e boas perspectivas de utilização nas etapas de separação e purificação de biodiesel.

$\mathrm{Na}$ área de produção de biodiesel, existem estudos publicados, dentre eles um focado no emprego de membranas na etapa de purificação, após a separação por decantação (SALEH et al., 2011). A utilização de membranas na separação do glicerol, sem decantação prévia, foi estudada em trabalhos anteriores (GOMES et al., 2011) e os resultados mostraram grande potencial de aplicação.

\section{OBJETIVO GERAL}

O objetivo geral é analisar a aplicabilidade do processo de ultrafiltração com membranas cerâmicas na separação e purificação do biodiesel etílico produzido a partir de óleos de soja refinado e degomado.

\section{OBJETIVOS ESPECÍFICOS}

Os objetivos específicos são: produzir biodiesel a partir de óleos de soja (degomado e refinado); analisar a proporção de água acidificada adicionada na mistura; aplicar a ultrafiltração na etapa de purificação; analisar o fluxo permeado da membrana; analisar a retenção de impurezas na membrana; analisar a qualidade do produto final pela análise do glicerol livre no permeado.

\section{METODOLOGIA}

Os experimentos foram realizados com óleo de soja refinado e degomado, ambos fornecidos pela Cooperativa Agroindustrial Cocamar (Maringá, Paraná) com as seguintes características, determinadas de acordo com a metodologia da AOCS: óleo refinado, 
densidade de $917,60 \mathrm{~kg} / \mathrm{m}^{3}$ e 0,43\% de acidez e óleo degomado, densidade $921,67 \mathrm{~kg} / \mathrm{m}^{3}$ e $0,93 \%$ de acidez. A reação de transesterificação foi realizada em balão de fundo chato de 3 bocas acoplado a um sistema com agitador e banho termostático, conforme as condições ótimas sugeridas por Gomes et al. (2011), a saber, razão molar óleo:álcool de $1: 7,5,1 \%$ de catalisador em relação à massa de óleo, sendo temperatura de $45{ }^{\circ} \mathrm{C}$ para $\mathrm{o}$ óleo de soja refinado e $30^{\circ} \mathrm{C}$ para o óleo degomado. A reação se processou por 1 hora.

A umidade presente na mistura reacional obtida forma uma emulsão com o triacilglicerol, o álcool em excesso, o catalisador e o glicerol, que dificulta o processo de separação por membranas. Então, foi adicionada água acidificada $(0,5 \% \mathrm{HCl})$ na concentração mássica de $10 \%$ em relação à massa total de mistura, para neutralizar o catalisador e transformar os sabões em sais solúveis em água, de forma a se ter uma fase dispersa aquosa, contendo substâncias solúveis em água, diminuindo a miscibilidade do glicerol nos ésteres e facilitando a coalescência das moléculas de glicerol, água, sais e álcool, formando aglomerados maiores que ficam retidos na membrana.

Esta mistura foi alimentada no módulo de micro e ultrafiltração UF NETZSCH modelo 027.06-1C1/07-0005/AI, instalada no Laboratório de Processos de Separação $\mathrm{DEQ} / \mathrm{UEM}$. Esta unidade contém membranas cerâmicas de $\alpha-\mathrm{Al}_{2} \mathrm{O}_{3} / \mathrm{TiO}_{2}$ (Shumacher GmbH-Ti 01070) em módulo tubular com comprimento de $250 \mathrm{~mm}$, diâmetro de $7 \mathrm{~mm}$, área de filtração de $0,005 \mathrm{~m}^{2}$ e diâmetros médios de poros de $0,05 \mu \mathrm{m}$ e $20 \mathrm{kDa}$. Neste módulo, os experimentos foram realizados na pressão de $10^{5} \mathrm{~Pa}$, regulada por válvula manual e temperatura de $50 \stackrel{\circ}{\circ}$, controlada por um banho termostático. Todos os experimentos foram realizados com uma vazão de $750 \mathrm{~L} / \mathrm{h}$. Ao final do processo, o permeado foi coletado e o concentrado totalmente recirculado para o tanque de alimentação. O fluxo permeado foi obtido por meio da determinação da massa de permeado coletada em função do tempo, medida em uma balança semi-analítica (BG 4000 - Gehaka), e calculado de acordo com a equação 1.

$$
I_{\text {perm }}=\frac{m_{p}}{A . t}
$$

em que $J_{\text {perm }}$ é fluxo $\left(\mathrm{kg} / \mathrm{h} . \mathrm{m}^{2}\right), m_{p}$ é massa de permeado $(\mathrm{kg})$ recolhida no intervalo de tempo $t(\mathrm{~h})$ e $A$ é área de permeação da membrana $\left(\mathrm{m}^{2}\right)$. O permeado obtido foi levado a um sistema de evaporador rotativo operando à vácuo $(600 \mathrm{mmHg})$ acoplado a um banho termostático à $65^{\circ}$, para retirada de álcool restante na amostra. 
Após a evaporação, o biodiesel passou por análise de densidade, em que se utilizou um picnômetro de $25 \mathrm{~mL}$ previamente calibrado com água destilada, e análise do teor de glicerol livre, feita por meio de metodologia modificada da AOCS (Ca 14-56), sugerida por Dantas, 2006. O percentual mássico de glicerol foi calculado de acordo com a equação apresentada por GOMES et al., 2011.

Após o ensaio de ultrafiltração, foi feita a limpeza das membranas, que continham placas de glicerol incrustadas na superfície (tortas). Para isso, as membranas foram colocadas em seguidos banhos ultrassônicos com soluções de $\mathrm{NaOH} 1 \%$, ácido cítrico $1 \%$ e água deionizada (neutraliza o $\mathrm{pH}$ da membrana) a $70^{\circ} \mathrm{C}$, por 12 minutos cada vez, repetidas vezes, até que a solução estivesse totalmente limpa.

\section{RESULTADO (S)}

Pode-se inferir do Gráfico 1, de fluxo para mistura reacional de óleo de soja refinado para as duas membranas, que no início da filtração, o aumento da concentração da fase dispersa na superfície da membrana de $0,05 \mu \mathrm{m}$ proporciona uma resistência adicional à permeação, ocasionando uma queda no fluxo de permeado. Com o passar do tempo, essa resistência diminui, já que o diâmetro de poro maior facilita que aglomerados menores (deformados devido ao efeito da pressão) adentrem os poros da membrana levando à visualização do fenômeno de polarização da concentração e fouling do fluxo. Porém, para a membrana de $20 \mathrm{kDa}$ não há declínio no início, pois o diâmetro de poro é menor e a fase aquosa retida na sua superfície não pode permeá-la. Com isso, uma maior quantidade de biodiesel permeia a membrana, fazendo com que a fase contínua se concentre em glicerol, causando aumento de concentração na superfície da membrana, que se compacta formando a torta, acusando a queda brusca do fluxo. Para os diferentes diâmetros de poros da membrana, o fluxo se estabeleceu em valores muito próximos. 


\section{S}

Fórum Ambiental

da Alta Paulista

ISSN 1980-0827
Volume 9, Número 1, 2013

Aplicação de Novas

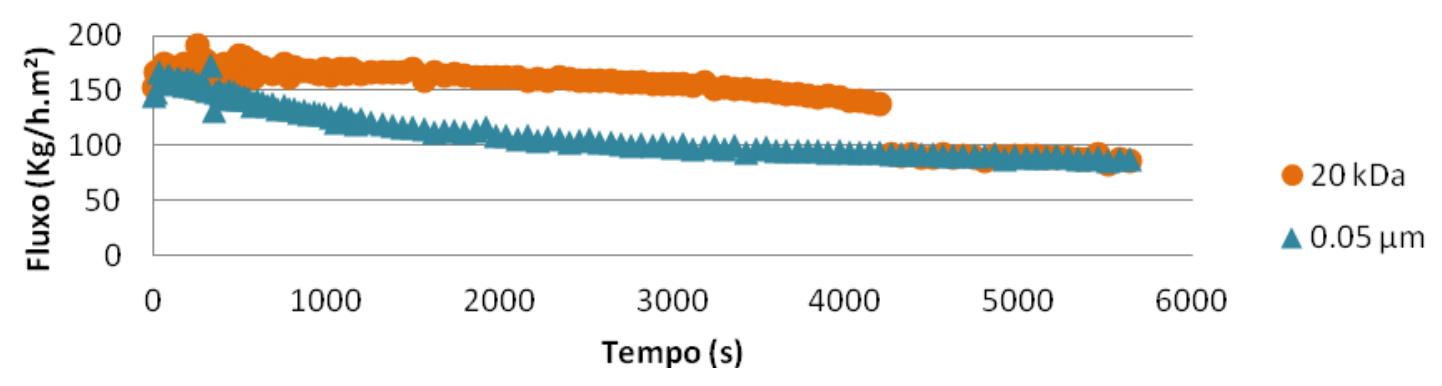

Gráfico 1: Fluxo permeado em função do tempo de filtração, para mistura reacional de óleo de soja refinado com $10 \%$ de água acidificada $(0,5 \% \mathrm{HCl})$, Membranas $0,05 \mu \mathrm{m}$ e $20 \mathrm{kDa}, 10^{5} \mathrm{~Pa}, 50^{\circ} \mathrm{C}$.

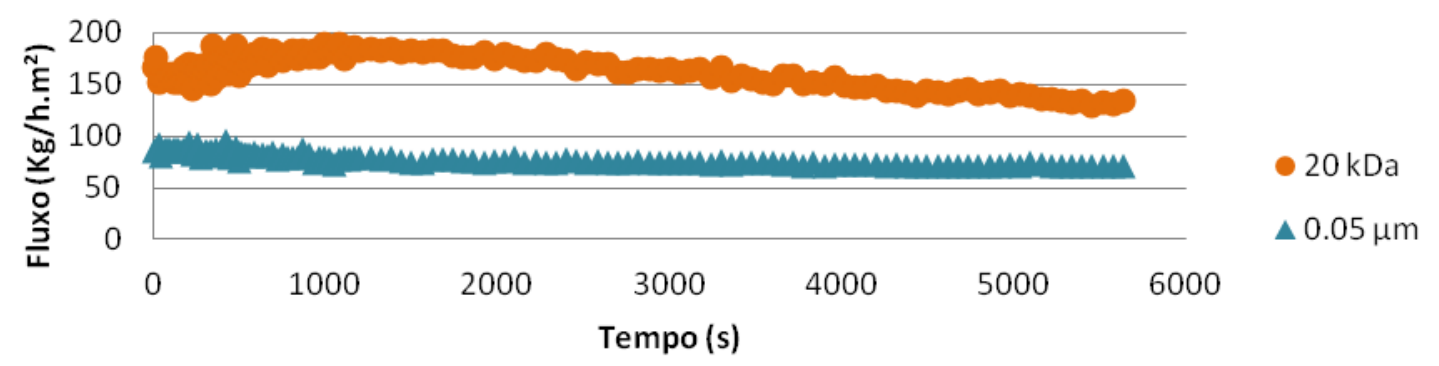

Gráfico 2: Fluxo permeado em função do tempo de filtração, para mistura reacional de óleo de soja degomado com $10 \%$ de água acidificada $(0,5 \% \mathrm{HCl})$, Membranas $0,05 \mu \mathrm{m}$ e $20 \mathrm{kDa}, 10^{5} \mathrm{~Pa}, 50^{\circ} \mathrm{C}$.

Os fluxos obtidos na ultrafiltração da mistura reacional produzida a partir do óleo de soja degomado são apresentados no Gráfico 2 acima. Percebe-se que a maior acidez do óleo de soja degomado, favorece a coalescência da fase aquosa, proporcionando a formação de aglomerados de glicerol de maior tamanho. Consequentemente, há uma menor queda do fluxo para os dois diâmetros de poro avaliados, pois o fenômeno de polarização da concentração na superfície da membrana é compensado pelo efeito difusivo mássico favorecido pelo fluxo. Com isso, o efeito fouling é reduzido, havendo uma queda suave do fluxo, ou até mesmo um aumento do fluxo no início do processo, como para a membrana de 20kDa. Isso ocorre devido ao fato dessa membrana possuir um menor diâmetro de poro, assim há pouca aderência dos aglomerados na superfície, o qual é compensado pelo efeito difusivo. Já na membrana de 0,05 $\mu \mathrm{m}$, o maior diâmetro de poro favorece a aderência dos aglomerados na superfície, havendo a formação de torta que oferece uma resistência ao fluxo e, consequentemente, sua queda. Como resultado, o fluxo permeado estabilizado é maior para a membrana de menor tamanho de poro.

Segundo as normas da ANP (2011), a densidade do biodiesel deve estar na faixa $850-900 \mathrm{~kg} / \mathrm{m}^{3}$ e o teor de glicerol deve ser menor que $0,02 \%$. Portanto, analisando os 
dados das Tabelas 1 e 2, verifica-se que ambos os óleos, proporcionaram biodiesel comercialmente satisfatório em relação à densidade. Já analisando o teor de glicerol, a purificação do biodiesel de óleo degomado proporcionou resultado dentro das especificações, enquanto a de óleo refinado apresentou variância nos valores, sendo alguns acima do limite de especificação, sendo considerado insatisfatório.

Tabela 1: Teor de glicerol e densidade do biodiesel de óleo de soja refinado tratado com água acidificada $\left(10 \% \mathrm{H}_{2} \mathrm{O}: 0,5 \% \mathrm{HCl}\right)$ e purificado a $10^{5} \mathrm{~Pa}$ e $50{ }^{\circ} \mathrm{C}$

\begin{tabular}{cccc}
\hline Membrana & Glicerol (\%) & Fase Aquosa (\%) & Densidade $\left(\mathbf{k g} / \mathbf{m}^{3}\right)$ \\
\hline $0,05 \mu \mathrm{m}$ & & 10,87 & 874,30 \\
$0,05 \mu \mathrm{m}$ & 0,0077 & - & 874,40 \\
$20 \mathrm{kDa}$ & 0,0102 & - & 872,90 \\
$20 \mathrm{kDa}$ & 0,0210 & - & 874,80 \\
\hline
\end{tabular}

Tabela 2: Teor de glicerol e densidade do biodiesel de óleo de soja degomado tratado com água acidificada $\left(10 \% \mathrm{H}_{2} \mathrm{O}: 0,5 \% \mathrm{HCl}\right)$ e purificado a $10^{5} \mathrm{~Pa}$ e $50{ }^{\circ} \mathrm{C}$

\begin{tabular}{cccc}
\hline Membrana & Glicerol (\%) & Fase Aquosa (\%) & Densidade $\mathbf{( k g / \mathbf { m } ^ { 3 } )}$ \\
\hline $0,05 \mu \mathrm{m}$ & 0,0010 & - & 870,00 \\
$0,05 \mu \mathrm{m}$ & 0,0007 & - & 869,70 \\
$20 \mathrm{kDa}$ & 0,0009 & - & 870,60 \\
$20 \mathrm{kDa}$ & 0,0011 & - & 869,90 \\
\hline
\end{tabular}

\section{CONSIDERAÇÕES FINAIS}

A ultrafiltração da mistura reacional obtida a partir do óleo de soja refinado não foi eficiente na remoção do glicerol, pois levou a casos de teor acima de 0,02\%. Já a maior acidez do óleo de soja degomado fez com que o biodiesel produzido apresentasse características dentro dos limites especificados pela ANP, fazendo com que o processo utilizado se mostrasse mais vantajoso para este biodiesel. Pode-se dizer que a purificação de biodiesel por ultrafiltração apresenta vantagens por não necessitar decantação prévia para separação das fases e reduzir a quantidade de água utilizada na lavagem.

\section{REFERÊNCIAS}


ANP, 2011. Agência Nacional do Petróleo, Gás Natural e Biocombustíveis. Relatório Mensal do Biodiesel. Disponível em <http://www.anp.gov.br/?pg=58819\&m=\&t1=\&t2=\&t3 $=\& t 4=\& a r=\& p s=\&$ cachebust $=1325941677039>$ Acesso em: 06 agosto 2013.

DANTAS, M. B. Obtenção, caracterização e estudo termoanalítico de biodiesel de milho. 2006. Dissertação (Mestrado em Química - Centro de Ciências Exatas e da Natureza, Universidade Federal da Paraíba, João Pessoa, 2006).

GOMES, M. C. S.; PEREIRA, N. C.; AROOYO, P. A. Biodiesel production from degummed soybean oil and glycerol removal using ceramic membrane. Journal of Membrane Science, v. 378, p. 453 - 461, 2011.

SALEH, J.; DUBÉ, M.A.; TREMBLAY, A.Y. Separation of glycerol from FAME using ceramic membranes. Fuel Processing Technology, v. 92, p. 1305-1310, 2011.

VAN GERPEN, J.; SHANKS, B.; PRUSZKO, R.; CLEMENTS, D.; KNOTHE, G. Biodiesel Production Technology. Nacional. Midwest Research Institute, Renewable Energy Laboratory, p. 105, 2004. 